\title{
LOS HUMEDALES RAMSAR EN ESPAÑA. REFLEXIONES A PROPÓSITO DE SU TRIGÉSIMO ANIVERSARIO
}

\author{
David Serrano Giné \\ Departament de Geografía \\ Facutad de Turismo y Geografía \\ Universitat Rovira i Virgili (Tarragona)
}

\section{RESUMEN}

Se reflexiona sobre los humedales españoles incluidos en el Convenio Ramsar. Después de una sucinta contextualización, se reseñan sus principales rasgos territoriales y se aborda su caracterización desde distintos puntos de vista, a saber: localización, naturalidad, estructura física y génesis, entre otros aspectos de índole ambiental en los que ha resultado de gran apoyo la consulta de bibliografía especializada. Esta aproximación permite detectar distintas problemáticas que deben encarar estos espacios, como es el caso de las relacionadas con el acceso y calidad del agua, las afecciones territoriales o las ligadas a su aprovechamiento y gestión. Se hace hincapié en la inconsistencia del listado español, hecho que lleva proponer un intencionadamente breve recuento de zonas húmedas susceptibles de ser consideradas por el Convenio.

Palabras clave: Convenio Ramsar, humedal, zona húmeda, espacio natural protegido.

\section{ABSTRACT}

The paper is about the Spanish wetlands included in the Ramsar Convention. An introduction is made outlining its main territorial features; after comes a characterization, discussed from different points of view, such as geographical location, natural degree, physical structure and genesis, among others aspects for which specialized literature has been of great advice. This approach detects different problems to face, such as those related to access and water quality, terrain degradation or degradation associated with its use and management. Finally a brief systematization of contents is made, focusing on the inconsistency of Ramsar's Spanish network. An intentionally brief account of wetlands to consider is added.

Key words: Ramsar Convention, wetland, natural protected area. 


\section{Introducción}

El 40 aniversario, en 2011, del Convenio Ramsar y el 30 aniversario, en 2012, de la adhesión española son un feliz pretexto para reflexionar sobre las zonas húmedas españolas amparadas por esta iniciativa internacional.

La Convención relativa a los humedales de importancia internacional especialmente como hábitat de aves acuáticas, más conocida como Convenio Ramsar, es un tratado internacional que tiene por objeto la protección de zonas húmedas. Como se ha notado en distintas ocasiones, este es el primer tratado moderno intergubernamental sobre conservación de recursos naturales, el único que dirige su atención hacia un ecosistema concreto y el pionero en establecer acuerdos de protección con manifiesta obligación jurídica para las partes firmantes. También es precursor en reconocer las relaciones de interdependencia entre ser humano y ambiente, explicitadas un año más tarde en la Declaración de Estocolmo, y adelantado en el uso racional de los recursos, idea conceptualizada con dieciséis y veintiún años de posteridad por la Comisión Brundtland y la Declaración de Río (Aldayturriaga, 1995, Blasco, 2002; Mulero, 2004). En el caso de España el Convenio Ramsar ha contribuido, también, al reconocimiento social y normativo de los humedales, tradicionalmente inexistente, cuando no divergente, según lo promulgado por la Ley Cambó, de 1918, la Ley de Aguas de 1866 o la de 1879, que estuvo en vigencia durante más de un siglo (Martín Mateo, 1981).

\subsection{Aspectos generales}

En su artículo primero la Convención apunta que por humedales se refiere a «extensiones de marismas, pantanos y turberas, o superficies cubiertas de aguas, sean éstas de régimen natural o artificial, permanentes o temporales, estancadas o corrientes, dulces, salobres o saladas, incluidas las extensiones de agua marina cuya profundidad en marea baja no exceda seis metros», para precisar en el artículo segundo que "podrán comprender sus zonas ribereñas o costeras adyacentes, así como las islas o extensiones de agua marina de una profundidad superior a los seis metros en marea baja, cuando se encuentren dentro del humedal, y especialmente cuando tengan importancia como hábitat para las aves acuáticas» (Ramsar Bureau, 1971). Se trata a todas luces de una definición muy amplia, que recoge la diversidad de formaciones que, bajo una designación u otra, se asimilan a zonas húmedas (Mitsch y Gosselink, 2000; Schnack, 2006). Pero que, sin embargo, dificulta el establecimiento de límites, su recuento e, incluso, caracterización (Casado y Montes, 1995).

De esta propuesta se infiere un interés por los hábitats acuáticos y semiacuáticos, y una preferencia por los valores faunísticos que albergan, tal como explicita el título completo del Convenio y la oración final de su artículo segundo. En efecto, el espíritu inicial de la Convención se dirigía a proteger la avifauna de zonas húmedas, tanto para su aprovisionamiento, reproducción, hibernada o migración (Artículo 2.2: «en primer lugar deberán incluirse los humedales que tengan importancia internacional para las aves acuáticas en cualquier estación del año»), creando una suerte de red internacional de humedales protegidos. Quedaban en segundo lugar los organismos piscícolas, la flora, el funcionamiento de los ecosistemas y su «gran valor económico, cultural, científico y recreativo». Más tarde, según las Enmiendas de Regina, de 1987, los valores de orden ecológico, la diversidad genética, la geomorfología y los aspectos culturales tomaron mayor relevancia, pudiendo apelarse también en la consideración de humedales e iniciándose, así, un giro en el planteamiento inicial del Convenio (Alfonso, 2002; Mulero, 2002). 


\subsection{Espacios protegidos por el Convenio Ramsar}

Las primeras declaraciones de espacios Ramsar se produjeron en 1974, con 33 humedales repartidos en cuatro estados (Australia y los tres países escandinavos) (Ramsar Bureau, 2011). Hasta 1980 se produjeron 149 declaraciones más, que ampliaron la nómina de firmantes a 23. Desde esta fecha el número de espacios Ramsar prácticamente se ha doblado por década: durante el decenio de 1980 hubo 263 declaraciones en 26 nuevos países y en el decenio de 1990 se llegaron a las 552 inscripciones (un 18\% de las cuales correspondían al Reino Unido). En los diez años que siguen desde el 2000 se reconocieron 933 zonas húmedas, que sumadas a las de 2011 significan el 48,9\% del total. Resulta interesante observar que un $24 \%$ de estos humedales se encuentran en países iberoamericanos (si bien es cierto que en estas cifras participan de manera significativa 117 declaraciones mexicanas).

A finales de 2011 eran 160 los países firmantes del Convenio, casi 2.000 los espacios incluidos en la llamada Lista Ramsar y más de 200.000 las hectáreas protegidas. El mayor número de sitios Ramsar se encuentra en Europa, con prácticamente la mitad de declaraciones $(47,05 \%)$, seguido a distancia por África y Asia (15,6\% y 12,09\%, respectivamente). Sin embargo el mayor número de superficie protegida se localiza en el continente africano (36,7\%), antepuesto a América del Sur (19,27\%), Asia (12,56\%), Europa (12,96\%) y América del Norte $(12,17 \%)$, cifras que dejan imaginar la extensión de los humedales protegidos. Oceanía participa en un $4 \%$ de los espacios de la Lista, que comportan un 5,21\% de la superficie reconocida y que mayormente se explican por humedales costeros y arrecifes coralinos. Únicamente se cuenta una declaración Ramsar en la Antártida, que responde al territorio francés de ultramar Tierras australes y antárticas.

El número más habitual de espacios declarados por país es uno, que es el mínimo exigido para que un estado pueda acogerse al Convenio. Sin embargo el promedio estatal es de 12 . Un $44 \%$ de los países miembros ha declarado un número superior de humedales, y únicamente un $22 \%$ supera los 26 reconocimientos. El país con más declaraciones es el Reino Unido (168), si bien 14 de estos espacios no tienen carácter metropolitano. Siguen por orden México (123), España (68) y Australia (65), acompañados a cierta distancia por Italia (52), Noruega y Suecia (51) y Argelia (50). En cuanto a superficie protegida el valor promedio es $1.235,6$ ha, si bien la disparidad de cifras es notable. El país con más extensión declarada es Canadá (13.066,68 ha, que localiza los mayores espacios en el Ártico y la bahía de Hudson), seguido de Chad (12.405,1 ha, que acoge grandes llanuras de inundación y su parte proporcional del lago Chad) y la Federación Rusa (10.323,77 ha, que concentra los humedales de mayor dimensión en el Ártico, el Pacífico Norte y en estepas continentales).

No parece existir una correlación clara entre el número de humedales declarados, la extensión de los mismos, su localización geográfica y, menos aún, biogeográfica. Es por ello que resulta lógico pensar que la declaración de humedales Ramsar no se vincula tanto a su localización o a sus características ecológicas (ambos aspectos de máxima importancia en lo que respecta a las aves) como a la sensibilidad ambiental de los gobiernos que los proponen. Respecto a la superficie amparada por el Convenio tampoco se puede inferir un vínculo entre número de espacios y extensión total, aunque sí parece colegirse correspondencia entre superficie declarada y espacios geográficos poco poblados (Tabla 1).

Se cuentan 13 humedales transfronterizos (en ocasiones hasta entre tres Estados, como es el caso de las llanuras de inundación de la confluencia del Danubio, el Morava y el Dyje, entre Austria, la República Checa y Eslovaquia), aunque únicamente uno de ellos (Niumi-Saloum, entre Gambia y Senegal) se localiza fuera de Europa. Ello puede llevar a reflexionar sobre la importancia geopolítica de algunos de estos espacios, como ya se ha hecho para los de la cuenca mediterránea (Béthemont y Houssel, 1992). 
Tabla 1

DIEZ PRIMEROS PAÍSES EN NÚMERO Y SUPERFICIE RECONOCIDA POR EL CONVENIO RAMSAR. FUENTE: ELABORACIÓN PROPIA A PARTIR DE RAMSAR BUREAU, 2011

\begin{tabular}{|l|c|l|c|}
\hline \multicolumn{1}{|c|}{ Estado } & $\begin{array}{c}\text { Número de } \\
\text { sitios Ramsar }\end{array}$ & \multicolumn{1}{c|}{ Estado } & $\begin{array}{c}\text { Superficie de } \\
\text { sitios Ramsar (Ha) }\end{array}$ \\
\hline Reino Unido & 168 & Canadá & $13.066,68$ \\
\hline México & 123 & Chad & $12.405,10$ \\
\hline España & 68 & Federación Rusa & $10.323,77$ \\
\hline Australia & 65 & Congo & $8.454,26$ \\
\hline Italia & 52 & México & $8.340,62$ \\
\hline Noruega & 51 & Antiguo Sudán & $8.189,6$ \\
\hline Suecia & 51 & Bolivia & $7.894,47$ \\
\hline Argelia & 50 & Australia & $7.510,18$ \\
\hline Países Bajos & 49 & República Democrática del Congo & $7.435,62$ \\
\hline Irlanda & 45 & Perú & $6.784,04$ \\
\hline
\end{tabular}

Un número elevado de sitios Ramsar también se halla amparado por otras figuras de protección, ya sean de ámbito regional o estatal, ya de rango internacional. Existen 40 humedales incluidos dentro de lugares Patrimonio de la Humanidad, si bien en algunos casos se trata de distintas declaraciones Ramsar ubicadas en un mismo lugar Patrimonio de la Humanidad, como es el caso de los lagos Bogoria, Elmenteita y Nakuru, en el recientemente declarado Rift Valley de Kenia. En 122 casos los humedales protegidos coinciden con Reservas de la Biosfera, como es el caso de 20 declaraciones de México, siete de España y la Federación Rusa o cuatro de Alemania y el Reino Unido. Como es lógico en determinadas ocasiones las coincidencias Ramsar con Reservas de la Biosfera también lo son con lugares Patrimonio de la Humanidad, como ocurre con Great Sandy Strait, en Australia, el sector rumano del delta del Danubio, o el Coto de Doñana, en España (Ramsar Bureau, 2011).

\section{Los humedales Ramsar en España}

\subsection{Aspectos generales}

España es uno de los países con más espacios inscritos en la lista Ramsar. A finales de 2011 eran 68 las zonas húmedas declaradas, cifra que situaba el territorio español en el tercer lugar mundial y segundo europeo por sitios notificados (Reino Unido 168; México 123). La comunidad autónoma con más humedales amparados es Andalucía (25), seguida de lejos por Castilla-La Mancha (7), Comunidad Valenciana y País Vasco (6), Galicia (5), Cataluña (4), Aragón, Castilla y León, Comunidad Foral de Navarra, Extremadura e Islas Baleares (2) y el resto de autonomías (con un solo humedal inscrito en la Lista); las ciudades autónomas de Ceuta y Melilla no aportan ningún espacio. Entre Galicia y el Principado de Asturias existe el único humedal de carácter interautonómico, que en la Lista Ramsar se 


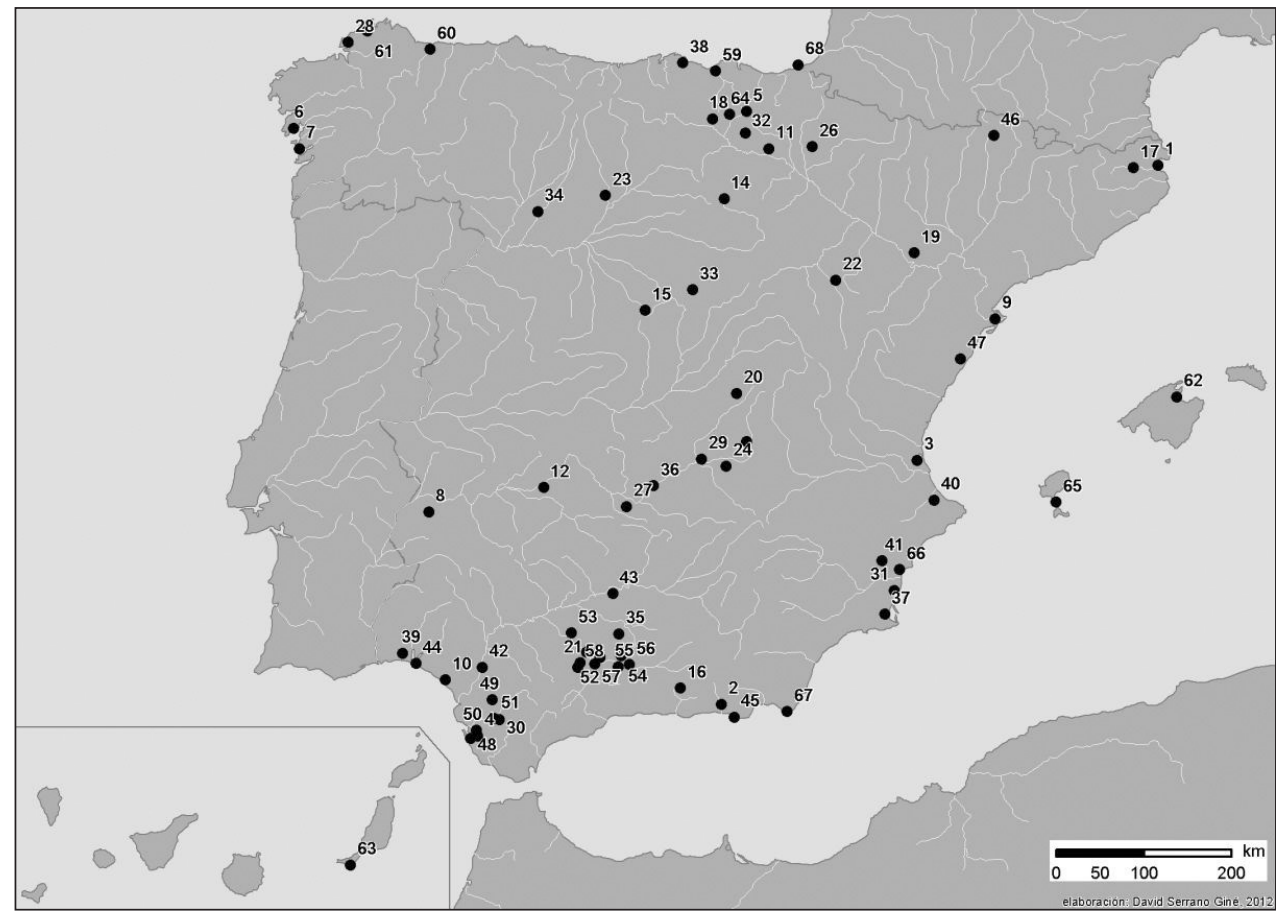

Figura 1. Humedales españoles incluidos en el Convenio Ramsar. 1. Aiguamolls de l'Empordà; 2. Albufera de Adra. 3; Albufera de Valencia. 4; Bahía de Cádiz. 5; Colas del Embalse de Ullibarri. 6; Complejo de Corrubedo; 7. Complejo intermareal Umia-Grove; 8. Complejo lagunar de La Albuera; 9. Delta del Ebro; 10. Doñana; 11. Embalse de las Cañas; 12. Embalse de Orellana; 13. Embalses de Cordobilla y Malpasillo; 14. Humedales de la Sierra de Urbión; 15. Humedales del Macizo de Peñalara; 16. Humedales y Turberas de Padul; 17. Lago de Banyoles; 18. Lago de Caicedo-Yuso y Salinas de Añana; 19. Laguna de Chiprana; 20. Laguna de El Hito, 21. Laguna de Fuente de Piedra; 22. Laguna de Gallocanta; 23. Laguna de la Nava de Fuentes; 24. Laguna de la Vega; 25. Laguna de Manjavacas, 26. Laguna de Pitillas; 27. Laguna del Prado; 28. Laguna y Arenal de Valdoviño; 29. Lagunas de Alcázar de San Juan; 30. Lagunas de Cádiz; 31. Lagunas de la Mata y Torrevieja; 32. Lagunas de Laguardia; 33. Lagunas de Puebla de Beleña; 34. Lagunas de Villafáfila; 35. Lagunas del sur de Córdoba; 36. Las Tablas de Daimiel; 37. Mar Menor; 38. Marismas de Santoña; 39. Marismas del Odiel; 40. Marjal de Pego-Oliva; 41. Pantano de El Hondo; 42. Paraje Natural Brazo del Este; 43. Paraje Natural Laguna Grande; 44. Paraje Natural Lagunas de Palos y Las Madres; 45. Paraje Natural Punta Entinas-Sabinar; 46. Parque Nacional de Aigüestortes i Estany de Sant Maurici; 47. Prat de Cabanes-Torreblanca; 48. Reserva Natural Complejo Endorreico de Chiclana; 49. Reserva Natural Complejo Endorreico de Espera; 50. Reserva Natural Complejo Endorreico de Puerto Real; 51. Reserva Natural Complejo Endorreico Lebrija; 52. Reserva Natural Laguna de los Jarales; 53. Reserva Natural Laguna de Tiscar; 54. Reserva Natural Laguna del Chinche; 55. Reserva Natural Laguna del Conde o El Salobral; 56. Reserva Natural Laguna Honda; 57. Reserva Natural Lagunas de Archidona; 58. Reserva Natural Lagunas de Campillos; 59. Ria de Mundaka-Guernika; 60. Ría del Eo; 61. Rías de Ortigueira y Ladrido; 62. S'Albufera de Mallorca; 63. Saladar de Jandía; 64. Salburua; 65. Salinas de Ibiza y Formentera; 66. Salinas de Santa Pola; 67. Salinas del Cabo de Gata; 68. Txingudi. 
designa como Ría del Eo, aunque en la toponimia oficial se refiera como Ría de Ribadeo (al menos en su vertiente gallega) (Figura 1).

La mayor superficie al seno del Convenio Ramsar se encuentra en Andalucía $(49,81 \%)$, seguida por el País Vasco $(12,23 \%)$, Castilla-La Mancha $(10,21 \%)$, Galicia $(8,04 \%)$ y Comunidad Valenciana $(6,5 \%)$. Sin embargo estos datos pueden inducir a engaño, pues siendo algunas de estas autonomías de las de mayor extensión o de las que albergan más humedales, se conoce que también puedan ser las que mayor superficie protegida ostenten. La proporción entre extensión protegida y extensión autonómica sitúa en primer lugar al País Vasco $(0,24 \%)$ con una separación de casi el 35\% respecto Andalucía $(0,07 \%)$, seguida de Comunidad de Madrid (0,06\%), Comunidad Valenciana y Galicia $(0,04 \%)$, Navarra $(0,03 \%)$ y Canarias, La Rioja y Castilla-La Mancha $(0,02 \%)$. Con todo, los estadísticos no deben hacer olvidar que la declaración de un humedal, y menos aún su importancia, no tienen porque responder únicamente a criterios de tipo cuantitativo.

Durante los años de 1980 se declararon 17 espacios Ramsar, la mayor parte en 1989. La década de 1990, en efecto, fue pródiga en incorporaciones, pues la nómina de humedales se cifra en 21, alcanzando el valor de 35 si también se contemplan los de 1989. La vorágine de estos años termina en 1996, no reanudándose la ampliación de espacios hasta 2002; durante los nueve primeros años de 2000 fueron 30 las propuestas incluidas en la Lista, esto es, el $44 \%$ de los 68 humedales reconocidos hasta la fecha.

\subsection{Caracterización}

La definición, caracterización, tipificación y clasificación de humedales ha sido objeto de un extenso debate, tanto epistemológico como procedimental (Rey Benayas et al., 1990; Rodríguez García y Pérez-González, 1999; Viñals, 1999; Sanz Donaire, 2000; Manzano, Borja y Montes, 2002; Schnack, 2006; Durán, García y Robledo, 2009). Desde la misma organización del Convenio Ramsar se han realizado ejercicios para sistematizar su caracterización (Ramsar Bureau, 2005) y su tipificación (Ramsar Bureau, 2009), entendiendo que incluso su misma identificación puede dar lugar a ambigüedades (MacKay et al., 2009).

Es común clasificar los humedales según su origen, cosa que da lugar a clasificaciones genéticas de orden hidrológico y geomorfológico. También resulta habitual establecer clasificaciones de tipo geológico, morfológico o hidromorfológico, según a qué aspecto del humedal se dirija la atención. Las clasificaciones de corte abiótico se complementan por aquellas otras de carácter funcional, ecológico y biológico; estas últimas, a su vez, dan lugar a distintas ordenaciones según los organismos que albergan y la consideración socioambiental de éstos. Evidentemente también se cuentan clasificaciones de tipo mixto con un planteamiento más o menos sistemático, como es el caso del Plan andaluz de humedales (2004) o el National Wetlands Inventory de Estados Unidos (2010), entre otros.

Atendiendo a su mera localización geográfica la proporción de humedales situados en la costa y en el interior es algo disimétrica (41,12\% y 54,41\%, respectivamente), predominando entre los primeros los del litoral mediterráneo (20,59\%). Los humedales de alta montaña, por su parte, tienen un carácter mucho menos pródigo (4 espacios), frecuentando las formaciones de tipo glaciar y escaseando las turbosas. El Plan estratégico español para la conservación y el uso racional de los humedales (1999) parte de una clasificación genético-funcional, muy minuciosa y estructurada, que se articula en torno la localización territorial de las zonas húmedas, según si se emplazan en ámbitos interiores (alta montaña, media montaña, cuencas de sedimentación, artificiales o de difícil clasificación) o costeros (atlánticos y mediterráneos). Cuanto a extensión, poco más de la mitad de los espacios 
$(51,47 \%)$ son de pequeña dimensión, o menos de $1 \mathrm{Km}^{2}$, según la clasificación de Viñals (1999) y poco menos de la mitad de tamaño medio $\left(1-10 \mathrm{Km}^{2}\right)$, no existiendo ninguno de tamaño grande o muy grande (10-100 Km² y más de $100 \mathrm{Km}^{2}$, respectivamente). Según la Directiva Marco del Agua (DMA), que considera de obligada declaración los cuerpos de agua de más de $0,5 \mathrm{Km}^{2}$, el 55,88\% de los humedales Ramsar entrarían en esta clasificación. Con todo hay que tener presente que estos valores se refieren stricto sensu a los espacios incluidos en la lista Ramsar, y no a la extensión real de la zona húmeda; así, por ejemplo, el área protegida del delta del Ebro es de $0,07 \mathrm{Km}^{2}$, si bien el delta como unidad territorial supera largamente los $300 \mathrm{Km}^{2}$.

Se conoce que el grado de naturalidad de los humedales españoles ha de entenderse de manera relativa (Pearce y Crivelli, 1994; OAPN, 1999). Partiendo de esta idea, la mayor parte de los sitios Ramsar se encuentran en lugares donde la intervención antrópica es baja o moderada, seis declaraciones se relacionan con aprovechamientos de tipo tradicional (Embalse de las Cañas, Lago de Caicedo-Yuso y Salinas de Añana, Embalse de El Hondo, Salinas del Cabo de Gata, Salinas de Ibiza y Formentera, Salinas de Santa Pola), y tres con obras hidráulicas de mayor antropización (embalses de Cordobilla y Malpasillo, Embalse de Orellana y Colas del Embalse de Ullibarri). Estos datos, sin embargo, deben ser tomados con cautela: en primer lugar porque la valoración de los humedales españoles es más próxima a la antropización que a la naturalización y, en segundo lugar, porque una lectura histórica de estos espacios puede revelar aparentes contradicciones, como ocurre, por ejemplo, en la Laguna Grande (Baeza) o en la laguna de La Nava (Palencia). Este último humedal antaño llegó a ocupar una extensión superior a las 2000 Ha, para ser completamente desecada en 1968, iniciarse su recuperación en 1990 y alcanzar poco tiempo más tarde las 307 Ha declaradas.

Focalizando en la estructura física del álvelo o cubeta del humedal, María José Viñals (1999) apunta unas características comunes a toda zona húmeda: topografía muy plana o levemente deprimida, proximidad del nivel freático y, en el caso de los humedales mediterráneos, elevada fluctuabilidad del régimen hidrológico. En cuanto a la morfología distingue aquellos humedales con álvelos ligados a depresiones endorreicas $(39,71 \%)$, relacionados con llanos costeros $(30,88 \%)$, de carácter artificial o artificializado $(11,76 \%)$, morfologías fluviales y cubetas cársticas (ambos con una participación del 8,82\%). La amplitud de esta aproximación favorece la inclusión de un humedal en más de una categoría, como sucede con las lagunas de Chiprana, formadas por combinación de procesos endorreicos y cársticos; la Laguna de Las Cañas, que inicialmente tenía carácter endorreico y más tarde artificial, por haberse recrecido con dos diques; los Humedales de la Sierra de Urbión, ubicados en topografías endorreicas de origen glaciar; o numerosas salinas litorales, como por ejemplo las de Ibiza y Formentera, ligadas a llanos costeros pero artificializados desde antiguo para favorecer la evaporación de agua y la obtención de sal.

Siguiendo a Durán, García de Domingo y Robledo (2009), los humedales se pueden clasificar desde un punto de vista genético-geológico. De tal manera un 60,29\% de los humedales son de tipo continental, mientras que los dos quintos restantes pertenecen al ámbito costero. Entre estos últimos dominan los regidos por génesis litoral mediterránea $(14,71 \%)$, seguidos por los de tipo fluvial mediterráneo (7,35\%). Las dinámicas fluviales en cuencas atlánticas de cifran en un 5,88\%, y a distancia aparecen las de tipo litoral $(2,94 \%)$. Los humedales caracterizados por una génesis mareal se localizan en su globalidad en el Atlántico, y participan en un 7,35\% del conjunto de espacios Ramsar. Las zonas húmedas de ámbito continental son mucho más abundantes, y aparecen claramente encabezadas por los humedales cársticos $(33,82 \%)$, seguidos a distancia por los de génesis fluvial $(16,18 \%)$. Las declaraciones en morfologías de origen glaciar se cifran en tres espacios y representan 
Tabla 2

HUMEDALES RAMSAR POR TIPO DE HÁBITAT

\begin{tabular}{|c|c|}
\hline Hábitat & Humedal Ramsar \\
\hline Adelfares & Prat de Cabanes-Torreblanca \\
\hline $\begin{array}{l}\text { Aulagares de Genista pumila mesomediterrá- } \\
\text { neos secos manchego-murcianos y setabenses }\end{array}$ & Laguna de Manjavacas \\
\hline $\begin{array}{l}\text { Brezal con aulagas y jaguarzos termomedite- } \\
\text { rráneo gaditano-onubense litoral }\end{array}$ & Doñana \\
\hline Comunidades de Ranunculus baudotii & Albufera de Valencia \\
\hline $\begin{array}{l}\text { Comunidades marinas, bénticas, infralitorales } \\
\text { de cormófitos y macrotalófitos }\end{array}$ & $\begin{array}{l}\text { Lagunas de La Mata y Torrevieja, Mar } \\
\text { Menor }\end{array}$ \\
\hline $\begin{array}{l}\text { Comunidades marinas, infralitorales de Posi- } \\
\text { donia oceanica }\end{array}$ & $\begin{array}{l}\text { s'Albufera de Mallorca, Salinas de Ibi- } \\
\text { za y Formentera, Salinas de Santa Pola }\end{array}$ \\
\hline $\begin{array}{l}\text { Encinares basófilos béticos andaluces-litora- } \\
\text { les y portugueses }\end{array}$ & Albufera de Adra \\
\hline $\begin{array}{l}\text { Encinares basófilos catalano-provenzales con } \\
\text { durillos }\end{array}$ & Lago de Banyoles \\
\hline Escobonal con rompesayos nevadense & Humedales y Turberas de Padul \\
\hline Fresnedas con melojos & Lagunas de Puebla de Beleña \\
\hline $\begin{array}{l}\text { Matorrales orotemplados pirenaicos de } \\
\text { Rhododendron ferrugineum }\end{array}$ & $\begin{array}{l}\text { Parque Nacional de Aigüestortes i Es- } \\
\text { tany de Sant Maurici }\end{array}$ \\
\hline $\begin{array}{l}\text { Matorrales pulvinulares de Genista occiden- } \\
\text { talis castellano-cantábricos }\end{array}$ & $\begin{array}{l}\text { Lagunas de Laguardia, Colas del Em- } \\
\text { balse de Ullibarri }\end{array}$ \\
\hline $\begin{array}{l}\text { Piornales serranos estrellenses, guadarrámi- } \\
\text { cos y bejarano-gredenses }\end{array}$ & Humedales del Macizo de Peñalara \\
\hline Retamares marianico-monchiquenses. & Embalse de Orellana \\
\hline Salviares mesomediterráneos secos riojanos & Embalse de Las Cañas \\
\hline Tarayales murciano-almerienses & Paraje Natural Punta Entinas-Sabinar \\
\hline $\begin{array}{l}\text { Tomillares gipsícolas termo-mesomediterrá- } \\
\text { neos semiáridos alicantinos }\end{array}$ & Embalse de El Hondo \\
\hline $\begin{array}{l}\text { Tomillares psicroxerófilos y basófilos de Thy- } \\
\text { mus mastigophorus castellano-cantábricos } \\
\text { septentrionales }\end{array}$ & $\begin{array}{l}\text { Lago de Caicedo-Yuso y Salinas de } \\
\text { Añana }\end{array}$ \\
\hline
\end{tabular}

un 4,41\% del total; otras génesis, como las morfológicas, de erosión diferencial, estructural o volcánica, apenas están representadas por un único espacio. Como bien apuntan los autores, estas clasificaciones han de entenderse desde el punto de vista del origen y, también, los procesos dominantes, que pueden actuar con distinta intensidad, a corto, medio o 
largo plazo, o incluso estar sujetos a diferentes dinámicas a lo largo de su evolución, como ejemplifican con la albufera de Adra.

Otras clasificaciones, como la de Manzano, Borja y Montes (2002), se dirigen a la caracterización hidrológica, estudiando el origen del agua, el modo de vaciado, el hidroperiodo y la tasa de renovación de aguas y sales, amén de la composición química del agua y la hidrodinámica. A pesar de las implicaciones notorias que la hidrología posee en la morfología, los procesos abióticos y las particularidades ecológicas de cada humedal, la dificultad de estos estudios y la complejidad de las tipificaciones resultantes ha obstaculizado su difusión. Con todo pueden establecerse dos grandes agrupaciones, según si los humedales son de tipo lenítico, o de aguas estancadas, o de tipo lótico, o de aguas corrientes. Los primeros resultan claramente mayoritarios $(82,35 \%)$ y se encuentran bien representados por lagunas y depresiones de tipo cárstico, endorreico o glaciar, mientras que los segundos se describen principalmente por marismas y zonas intermareales.

La cartografía de hábitats a 1:50.000, la disponible para el conjunto del Estado español, únicamente permite realizar identificaciones con hábitats comunitarios en un 32,4\% de los humedales declarados. De estos 22 espacios, tres se corresponden a comunidades marinas infralitorales de Posidonia oceanica, tres a matorrales orotemplados pirenaicos de Rhododendron ferrugineum y dos a comunidades marinas bénticas infralitorales de cormófitos y macrotalófitos; el resto de espacios coincidentes únicamente se identifica con un tipo de hábitat comunitario (Tabla 2). Del conjunto de lugares analizado cinco espacios aparecen incluidos en hábitats prioritarios: las praderas de posidonia (3 declaraciones), vegetación hidrofítica y tomillares gipsícolas (ambos con una sola declaración). Con la misma cautela cartográfica debe considerarse la coincidencia con la ocupación del suelo, según los datos de 2006 a 1:100 000 del proyecto Corine. La mayor parte de declaraciones $(25,81 \%)$ coinciden con tierra de labor en secano, siguiendo a larga distancia $(11,29 \%)$ los olivares y los mosaicos de cultivos $(6,45 \%)$. Otras ocupaciones con una participación moderada son los arrozales, viñedos y distintos tipos de bosques y matorrales. Por el contrario determinadas ocupaciones que, a priori, parecerían corresponderse con humedales, como marismas, salinas o lagunas costeras, no presentan una participación significativa (un único espacio declarado). A modo anecdótico cabe citar la existencia de espacios Ramsar en lugares cartografiados como tejido urbano discontinuo (Laguna y arenal de Valdoviño), zonas portuarias (Laguna de la Mata y Torrevieja) o campos de frutales (Marjal de Pego-Oliva), explicables por una unidad mínima cartografiable de $25 \mathrm{Ha}$ y una cierta proximidad de usos. A propósito de la Laguna y arenal de Valdoviño es interesante notar la controversia aparecida a raíz del aumento de capacidad de recogida del vaso de la laguna de A Frouxeira, sus implicaciones en la inundación del área urbana de Valdoviño y sus posibles efectos perniciosos en las especies y hábitats que motivaron su protección, según ha hecho notar la Sociedade Galega de Historia Natural (SGHN, 2012).

Una caracterización de humedales con importancia para las aves resulta incompleta sin una referencia expresa hacia la ornitofauna. Podría parecer lógico reflexionar sobre la importancia de los humedales Ramsar en lo que respecta a abundancia y distribución de aves, a la existencia de determinadas categorías de estado de conservación (habitualmente especie extinguida, en peligro, vulnerable, rara, indeterminada o insuficientemente conocida) o a su importancia corológica (según si se atiende a especies residentes, con permanencia estival, invernada fuerte, invernada floja o paso migratorio). Pero conviene tener presente que, exceptuando espacios de gran dimensión, localización geográfica o elevado valor ambiental, estas atribuciones no recaen en los humedales sino en la fauna que los habita, existiendo humedales con un elevado valor migratorio para determinadas especies y nulo valor estival o invernante para otras. Estos parámetros de valoración, como resulta lógico 
pensar, varían según las aves estudiadas y, en función de éstas, se aplican a un espacio u otro, no por su propia naturaleza, sino por la función ornitológica que cumplen.

El rango de protección ambiental de los espacios declarados es variable. Aparte de estar amparados por la Convención Ramsar, en numerosos casos también se superponen distintas figuras de protección, como es habitual en la legislación española. Cuatro humedales Ramsar se hallan incluidos en parques nacionales (Aigüestortes i Estany de Sant Maurici, Doñana, Humedales y Turberas de Padul y Tablas de Daimiel) y catorce en parques naturales (Aiguamolls de l'Empordà, Albufera de Valencia, Complejo de Corrubedo, Delta del Ebro, Humedales del Macizo de Peñalara, Lagunas de la Mata y Torrevieja, Mar Menor, Marismas de Santoña, Marjal de Pego-Oliva, Pantano de El Hondo, s'Albufera de Mallorca, Salinas de Ibiza y Formentera, Salinas de Santa Pola, y Salinas del Cabo de Gata). De la misma forma también hay que considerar otras declaraciones, como los espacios PEIN o las reservas, entre las que se encuentran once reservas naturales andaluzas y que, en su conjunto, configuran un heterogéneo entramado de formas y figuras de protección (Troitiño et al., 2005).

\section{Problemas y retos ambientales}

Los problemas que afectan a los humedales han sido referidos en obras de carácter general, como el trabajo de Mitsch y Gosselink (2000) y el de Keddy (2002), o en documentos con carácter normativo como, por ejemplo, el Plan Estratégico Español para la Conservación y el uso Racional de los Humedales (OAPN, 1999). Este último, en efecto, señala cinco aspectos en los que fijar atención: caudales y coordinación con la planificación hidrológica, incidencia de la gestión hidrológica en la creación o desaparición de humedales, integración de la planificación hidrológica con la de los humedales y conservación de tramos de ríos en estado natural. Siguiendo a Antonio Camacho (2008) los principales impedimentos que afrontan las zonas húmedas se pueden agrupar en cuatro apartados: alteración del hidroperiodo, alteración de la calidad del agua, alteración del territorio, y dificultades de uso y gestión.

\subsection{Alteración del hidroperiodo}

Los cambios artificiales del hidroperiodo son una de las alteraciones de mayor impronta fisiognómica en los humedales. Los cambios más drásticos se producen con la desecación total del humedal, como en el ya citado caso de La Nava, y el consiguiente cambio de ocupación del suelo, habitualmente hacia cultivos. La legislación española tradicionalmente ha favorecido estas actuaciones bajo premisas de tipo sanitario y productivista, tanto en normativas históricas como vigentes. De hecho la actual Ley de Aguas ${ }^{1}$, vigente desde 2001, en el punto seis de su artículo 111, indica: «[a]simismo, los Organismos de cuenca, previo informe favorable de los órganos competentes en materia de Medio Ambiente, podrán promover la desecación de aquellas zonas húmedas, declaradas insalubres o cuyo saneamiento se considere de interés público».

La extracción de agua, infiltrada o exfluviada, merma el estado ambiental de los humedales. El caso más paradigmático sea probablemente el de Tablas de Daimiel, donde la explotación del río Guadiana, en superficie, y del acuífero 23, en profundidad, ha provocado

1 El RDL 1/2001, de 20 de julio, aprueba un texto refundido de la Ley de Aguas, que parte esencialmente de la Ley 29/1982, de 2 de agosto, pero incluyendo modificaciones como las desarrolladas por la Ley 46/1999, de 13 de diciembre, de modificación de la Ley 29/1985, y otras disposiciones y sentencias, como la del Tribunal Constitucional 227/1988. 
su progresiva desecación. Ello motivó la apertura de distintas amonestaciones por parte de la Unesco (2008) y a la Comisión Europea (2009), que unas precipitaciones copiosas y extraordinarias a inicios de 2010 impidieron prosperar. En determinados humedales, como Caicedo-Yuso (Rico et al., 2004, citado por Camacho, 2008), el volumen de agua substraído provocaba variaciones de más de dos metros en el nivel del agua, con repercusiones en la fauna y la vegetación, aparte del funcionamiento propio del sistema. En lagos o embalses, como el de Orellana, esta alteración resulta particularmente significativa, pues comporta cambios en la estratificación térmica del agua con repercusiones en la existencia de organismos biológicos, amén de otras consecuencias propias de sistemas inestables y fluctuantes. Dicha coyuntura resulta particularmente problemática si se considera la propiedad del suelo, pues según lo dispuesto por el artículo 10 de la Ley de Aguas, la propiedad privada prevalece sobre la legislación en el caso de cuerpos de agua de pequeña entidad: «[1]as charcas situadas en predios de propiedad privada se considerarán como parte integrante de los mismos siempre que se destinen al servicio exclusivo de tales predios y sin perjuicio de la aplicación de la legislación ambiental correspondiente». No conocemos ningún espacio Ramsar donde se haya producido esta circunstancia, aunque ello no es óbice para la aparición en el futuro de posibles situaciones encontradas.

La alteración por exceso de agua también altera los ciclos propios de los humedales, los ritmos de fluctuación y, en definitiva, sus condiciones originarias. Resulta significativo notar que con ello, a menudo, también se modifican los motivos por los cuales se incluyeron en la lista Ramsar. En ocasiones las alteraciones son anteriores al reconocimiento de los humedales, como ocurre con el apresamiento de determinados lagos glaciares en Aigüestortes, que repercuten en la orla de vegetación helófita circundante. En otras ocasiones son posteriores, como el ya comentado caso de Valdoviño.

\subsection{Alteración de la calidad del agua}

De manera ligada a variaciones de la cantidad del agua, hay que evocar también las variaciones en la calidad del agua. Tradicionalmente la contaminación de aguas se ha realizado por la recepción de aguas negras de núcleos de población cercanos, que han utilizado lagos y lagunas como sumideros; este es el caso, por ejemplo, de la Laguna de la Vega, colectora de las aguas de la vecina población de Pedro Muñoz. Este humedal cambió su carácter salino al recibir primero las aguas sucias de la población sin depurar y, luego, ya depuradas (modificando, también, su hidroperiodo). Los humedales que recogen aportes de zonas agrícolas acostumbran a presentar elevados valores de eutrofización. Como es sabido, en este proceso un exceso de nutrientes del agua desemboca en un incremento desmesurado de la biomasa y, a su vez, en un descenso del oxígeno disponible en el medio. Casos como el de la Albufera de Valencia han sido estudiados desde hace años (Soria, Miracle y Vicente, 1987), y han terminado por convertirse como paradigmáticos de un tipo de contaminación (Casado y Montes, 1995). En lugares donde abreva el ganado o anida la avifauna también se detecta cierta eutrofización ligada a la acumulación de deyecciones.

Aparte de nutrientes, los humedales que recogen lixiviados de tierras de labor acostumbran a tener cargas importantes de biocidas utilizados en agricultura, así como de metales pesados, como el mercurio o el cinc. Pero es el plomo, sin duda, el elemento químico con mayores consecuencias ambientales, al ser causante de saturnismo (particularmente en la avifauna) y contaminar vegetales, suelos y aguas. Este problema se detecta en numerosos espacios Ramsar, como Doñana, el Delta del Ebro o el embalse de El Hondo (Suárez y Uríos, 1999). El RD 581/2001, por el cual se prohíbe el uso de perdigones de plomo para actividades cinegéticas en determinadas zonas húmedas, y el artículo 62 de la Ley 42/2007, 
del Patrimonio Natural y la Biodiversidad, ha comportado una reducción de plomo y plumbismo en estos lugares, aunque no su desaparición (Ecologistas en Acción, 2008).

Otras afecciones pueden relacionarse con variaciones en la estratificación de las aguas de los lagos, y también en las variaciones artificiales de temperatura y conductividad. Así sucede en Mar Menor, antaño con unas aguas mucho más cálidas y salinas que las del Mediterráneo, y en la actualidad prácticamente parejas, por causa de la ampliación y apertura de golas, como la del Estacio y Las Encañizadas, con fines turísticos.

\subsection{Alteración del territorio}

Las alteraciones del territorio, lato sensu, se identifican con cambios en la ocupación del suelo que afectan al funcionamiento de los humedales. Estos cambios pueden referirse a la substitución de ocupaciones, como el paso a tierras de labor, o a la intensificación de usos, como sucede en el caso de ciertas actividades agrarias. Recordando de nuevo la Albufera de Valencia se puede señalar la disminución del marjal y la lámina de agua a costa del cultivo del arroz y, a su vez, la mengua de éste por colmatación para el cultivo de cítricos. Se conoce que los humedales más sensibles a estos cambios son los endorreicos, por alimentarse de las aguas de escorrentía de su cuenca receptora, pero en sistemas tan frágiles como estos cualquier alteración se manifiesta fácilmente. Así, los cambios en las actividades tradicionales acostumbran a tener consecuencias directas en el funcionamiento de los humedales, como se ha observado con la dinámica sedimentaria del río Oka, en Mundaka-Guernika, o en la valoración de la diversidad, por ejemplo, en Corrubedo (Polo, 2010). La implantación de actividades urbanas ha llevado a una convivencia de usos que, a menudo, podría calificarse de inapropiada. Este sería el caso, talmente, de la Laguna de Prado, parcialmente colmatada en su margen sur-oeste por unas naves industriales y una plaza de toros; por Salburua, donde el único suelo no sellado se encuentra en el margen este de la laguna; en Santoña, donde el polígono industrial de la población colinda con el tramo final de la ría de Boo; en Mar Menor, donde prácticamente todo el cordón de la Manga ya se encuentra edificado; o en el saladar de Jandía, sin continuidad hacia en interior de la isla por causa de aprovechamientos turísticos. De manera ligada a estas modificaciones se encuentran los cambios en la conectividad del territorio, relacionados con la ocupación del suelo y, también, con la aparición de infraestructuras y sistemas de cerramiento parcelario. De esta guisa se podría comentar el caso de la Albufera de Adra (Figura 2), rodeada de invernaderos y aislada del resto del territorio formando, en efecto, paradójicas «islas de agua en un mar de tierra» (Paracuellos, 2007).

También en este capítulo se deben incluir los innumerables organismos alóctonos que pueblan estos espacios, y que no solo provocan cambios en ellos sino también en todo el territorio circundante. Entre la flora invasora destaca Carpobrotus edulis, en zonas litorales; Cortaderia selloana, particularmente abundante en los contornos de Santoña; o de Baccaris halimifolia, en Mundaka-Guernika, entre otras especies. Entre la fauna destaca el cangrejo rojo americano (Procambarus clarkii), que desplaza al cangrejo de río europeo (Austropotamobius pallipes); la tortuga de Florida (Trachemys scripta elegans), que compite por recursos y hábitat con otros galápagos autóctonos; o el pato malvasía canela (Oxyura jamaicensis), capaz de cruzarse con la autóctona malvasía cabeciblanca (Oxyura leucocephala) y criar individuos fértiles (Muñoz, Negro y Green, 2008). Se trata en todos casos de organismos naturalizados capaces de alterar hábitats y comportamientos de especies autóctonas y modificar, así, las condiciones propias de estos lugares. Bajo este prisma resulta oportuno recordar hasta qué punto pueden contemplarse los valores de biodiversidad como sinónimo de calidad ambiental y, como ya se ha señalado, en qué medida la fauna 


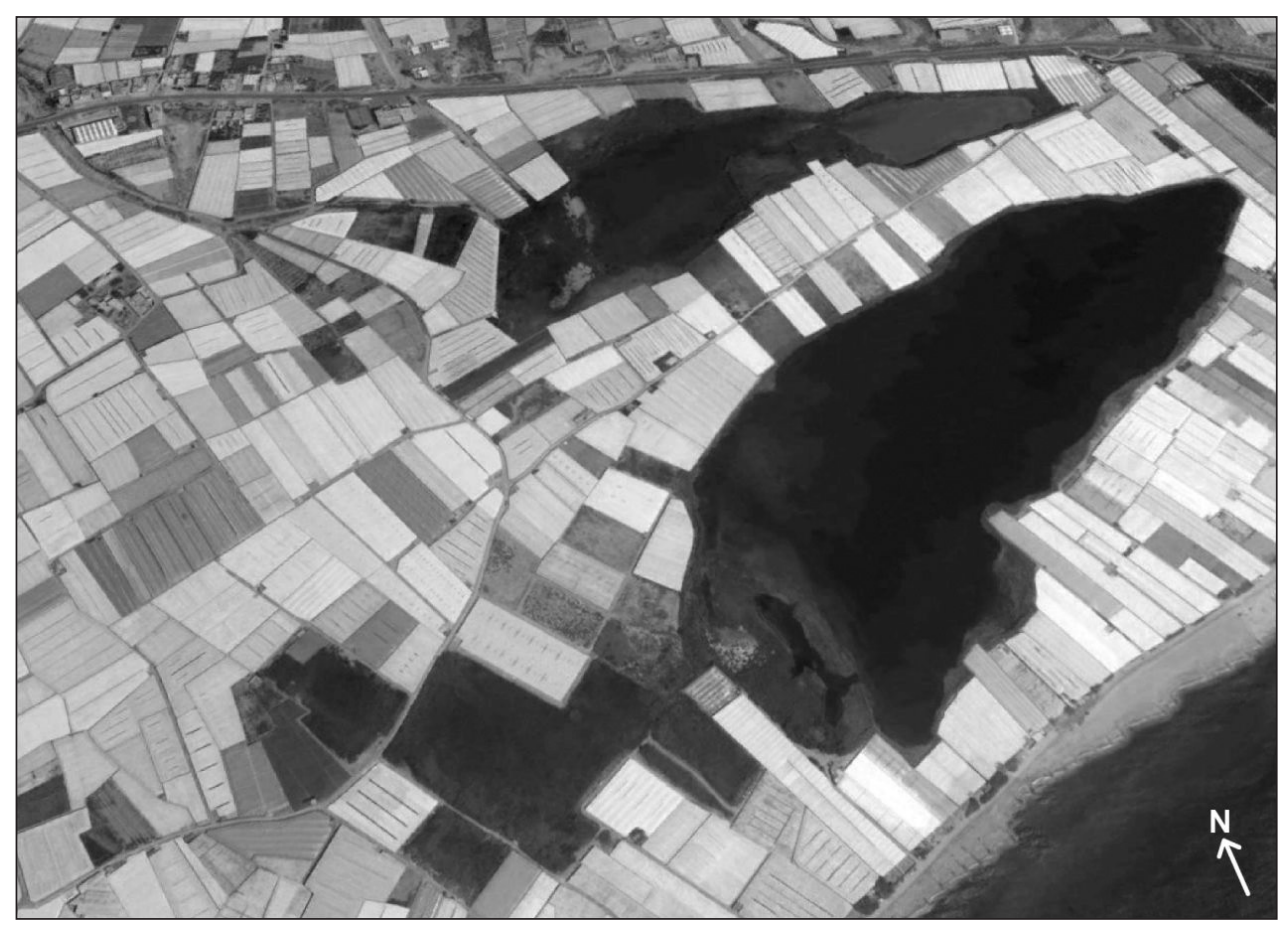

FIgURA 2. Imagen oblicua de la Albufera de Adra. Nota: la escala varía en esta perspectiva, del extremo este al extremo oeste de la Albufera Nueva (la lámina de agua más cercana a la costa) distan poco más de 1.025 metros. Fuente: Google Earth.

(particularmente la ornitológica) puede considerarse para estimar el valor de una zona húmeda (Casado y Montes, 1995).

\subsection{Dificultades de uso y gestión}

Como en cualquier espacio sujeto a actividades y regulaciones humanas, los humedales Ramsar también sufren dificultades relacionadas con su aprovechamiento y gestión. A pesar de que existen figuras de planeamiento dirigidas ex profeso a espacios naturales (por ejemplo PORN, PRUG o Planes Especiales), la inclusión de un humedal en el Convenio no comporta la obligatoriedad de redacción de ningún documento de carácter normativo (si bien el mismo Convenio recomienda hacerlo). La multiplicidad de figuras ambientales en España dificulta una sistematización de resultados, más aún si se atiende la dispersión de situaciones: según datos de EUROPARC (2010) un $80 \%$ de los parques naturales, un $40 \%$ de los nacionales y un $36 \%$ de las reservas del conjunto español disponen de instrumentos al efecto. La consolidación de la Red Natura 2000, que sí precisa la redacción de documentos de gestión, podría ayudar a corregir esta desviación, claro está, en aquellos humedales Ramsar que también fueran ZEC o ZEPA (algo que, por otra parte, la DMA contempla como obligatorio). La distribución de competencias derivada de la Ley 4/1989 y sus posteriores modificaciones establece las Autonomías como responsables del desarrollo de dicho planeamiento. Dado que la autoridad administrativa ante la Convención es el Ministerio de Agricultura, Alimentación y Medio Ambiente, y como ninguno de los 
humedales Ramsar españoles se encuentra adscrito también al Organismo Autónomo de Parques Nacionales, la elaboración de cualquier documento de manejo corre a cuenta de los gobiernos autonómicos o locales, es decir, Administraciones distintas a la titular.

De una manera similar cabe recordar las distintas competencias administrativas que pueden llegar a encontrarse en un ámbito dado, como puedan ser los humedales de gran extensión o los cercanos al litoral, según lo que dispone la Ley de Aguas 1/2001 y la Ley de Costas 22/1988. La yuxtaposición y coordinación de competencias se revela de manera manifiesta en la Albufera de Valencia (Camacho, 2008), donde el régimen hídrico del humedal se regula por sobrantes parcialmente establecidos por la Administración estatal a través de la Cuenca Hidrográfica del Júcar, la gestión del parque natural se fija por la Administración autonómica (Generalitat Valenciana) y la titularidad de la lámina de agua por la Administración local, a través de una cesión de Patrimonio Nacional al Ayuntamiento de Valencia. Los cuerpos de agua a menudo han sido utilizados como lindes entre municipios, como sucede en la Laguna de El Hito, entre el término de El Hito y el de Montalbo, por citar un único caso de la coyuntura administrativa que puede afectarse en la gestión de un humedal. Otras situaciones encontradas se hallan, por ejemplo, en las cesiones de agua del trasvase Tajo-Segura a las Tablas de Daimiel, (la primera de todas en 1987) no exentas de discusiones ambientales y territoriales. Las competencias sobre el uso de agua, con todo, parecen encontrarse lejos de una actuación con criterio unitario. Como es sabido, desde el punto de vista legislativo las Comunidades Autónomas son responsables de las cuencas intracomunitarias, y el Estado de las intercomunitarias. En octubre de 2008, según lo dispuesto en el Real Decreto 1666/2008, el Estado otorgó competencias sobre el uso del agua en la cuenca del Guadalquivir en su tramo correspondiente a Andalucía, pero no así a Extremadura, Castilla-La Mancha y Murcia en sus porciones correspondientes. Tres años más tarde se modificaba la Ley de Aguas (Real Decreto-Ley 12/2011) para que las Autonomías con previsión estatutaria al respecto (Andalucía, Aragón y Cataluña) asumieran competencias de policía sobre el dominio público hidráulico, de manera independiente de las actuaciones que pudieran realizarse en otras autonomías de la misma cuenca (aunque un Real Decreto de 4 de mayo de 2012 devolvía estas competencias al Estado).

No conviene olvidar, tampoco, los distintos usos que se reúnen en estos lugares. No siempre se trata de aprovechamientos afines a los propósitos observados por la Comisión sino que, en ocasiones, tampoco son compatibles entre ellos. Estamos hablando de actividades agropecuarias, como el cultivo del arroz o el aprovechamiento de pastos; actividades de carácter tradicional, como la siega de mimbre y espadañas o la recogida de plantas barrilleras; de aprovechamientos cinegéticos, incluyendo la caza deportiva y la pesca profesional; visitas turísticas, usos de ocio y recreo y muchos otros que pueden comportar altas concentraciones de personal y elevadas intensidades de uso en superficies acotadas ya de por sí frágiles.

\section{Discusión}

\subsection{Antecedentes}

Dejando de lado caracterizaciones y problemáticas diversas, probablemente el aspecto que mejor define la lista española de humedales Ramsar es su heterogeneidad y escasa consistencia territorial. Este hecho deriva de lo dispuesto por las Enmiendas de Regina de 1987 y por las transferencias autonómicas en materia de espacios naturales protegidos, y tiene unas consecuencias directas en el sentido y razón de ser del Convenio en cuanto figura de protección ambiental. 
Las Enmiendas de Regina señalan un cambio de concepción a la hora de incluir zonas húmedas al Convenio. Según estas disposiciones la importancia ornitológica deja de ser condición sine qua non para incluir un humedal en la Lista, abriéndose la puerta a aspectos relacionados con el funcionamiento, la geomorfología o determinadas consideraciones culturales. Bajo este nuevo enfoque los humedales Ramsar pasaban de constituir una red de humedales de importancia para las aves, a formar una red de humedales con importancia para las aves. Así se cedía paso de manera evidente a una trama internacional de espacios naturales centrada en un ecosistema (las zonas húmedas), y no únicamente en un grupo faunístico (las aves). Este planteamiento, mucho más completo que el anterior, connota una idea de consistencia entre todos los espacios que conforman la Lista: consistencia en cuanto a diversidad, singularidad, dimensión, naturalidad, representatividad, fragilidad y conectividad, aparte de otros criterios que, sin ser de tipo ecológico, se puedan relacionar con la planificación o la consideración cultural. Una consistencia que, sin haber sido formulada explícitamente por la Convención, sugiere la selección e inclusión de aquellos humedales de mayor relieve dentro de su género, no sólo en lo referente a las aves, sino también en lo que concierne a su localización, génesis, naturalidad y atributos naturales o culturales. Una consistencia que debe entenderse con coherencia, de manera internacional, por ser este el carácter de la Convención, y también de manera Estatal, por ser los Estados los responsables administrativos ante la Convención. Una consistencia, finalmente, que ha de servir para detectar a la postre aquellos humedales de mayor significado en su contexto, tanto temático como espacial.

En el Estado español el reparto de competencias sobre espacios naturales protegidos recae de manera íntegra en las autonomías. Al gobierno central únicamente afecta la declaración y coordinación de la red de parques nacionales, así como el establecimiento de «un marco adecuado» para su conservación, según dispone en su artículo 4 la Ley 5/2007. Es por ello que, aunque la responsabilidad administrativa ante la Comisión tenga carácter estatal, el planeamiento y ejecución de cualquier acción ligada a los espacios Ramsar únicamente podrá ser autonómico. Evidentemente ello dificulta tareas de concertación entre distintas administraciones y obstaculiza la creación de una red consistente, primero, y coherente, después, de humedales, que represente las características y valores de las zonas húmedas españolas.

Los humedales Ramsar españoles pueden considerarse más que suficientes (al menos en términos cuantitativos) si se contempla la tercera posición de España en el listado internacional. Pero distan mucho de ser consistentes en cuanto a su significado y coherentes respecto sus partes integrantes. Quizás no lo sean tanto desde el punto de vista de su importancia para las aves, pero sí en lo que respecta a selección de espacios bajo criterios de tipo ecológico, cultural o de planificación, como los que acostumbran a utilizarse para valorar el patrimonio natural (Mallarach, 1999). Es por este motivo que los humedales inscritos en el Convenio pueden considerarse integrantes de una red desde el punto de vista del interés para las aves, pero únicamente constituyentes de un listado desde el punto de vista de su naturaleza en tanto que ecosistema, porque su selección e inclusión no responde, mayormente, a criterios diferentes de los ornitológicos.

\subsection{Una propuesta abierta}

Se conoce distintas zonas húmedas, frecuentemente amparadas por otras figuras de protección, que no se hallan recogidas en el listado Ramsar y que, buscando una idea de completitud, quizás resultaría positivo observar. La propuesta que sigue no intenta realizar un estudio exhaustivo, tarea que recae fuera de los objetivos de este trabajo, y tampoco 
pretende reproducir ninguno de los catálogos de humedales ya existentes ${ }^{2}$. Nuestra propuesta tiene por intención recoger algunos de los humedales españoles que, a pesar de tener un significado o carácter especial, por no sobresalir en su importancia ornitológica, no se encuentran inscritos en la Convención. Se trata de zonas húmedas con interés por su localización, génesis, representatividad, singularidad, valor paisajístico o cultural que, sin prejuicio de hallarse amparadas por otras figuras de protección, merecerían incluirse en una red de humedales protegidos.

Se echa en falta en el listado español de humedales Ramsar una mayor representación de los sistemas asociados a rías y estuarios, poco frecuentes en el conjunto estatal. Son muestras de interés la ría de San Vicente de la Barquera y la vecina ría de La Rabia, ambas en Cantabria; la de Villaviciosa, en Asturias; la de Ortigueira, en la amplia desembocadura del río Mera, o la de Betanzos, que en su tramo final se une a la del Ares, también llamada del Eume, en A Coruña; los contornos de las Islas Malveiras, en la ría de Arousa (Pontevedra), incluidos en el parque nacional de las Islas Atlánticas; la ensenada de San Simón, que a su valor natural suma el histórico; o el estuario del Miño que, a pesar de encontrarse relativamente edificado y soportar cierta presión turística, no deja de resultar interesante, cuanto menos por su carácter internacional. Sucede de manera similar con la desembocadura del Guadiana, que reúne los esteiros de Teziria y Carrasqueira en la parte lusa y los caños del Pozo y de la Cruz en la española; o el tramo final del río Piedras, incluyendo la espectacular flecha del Rompido, también en Huelva. La Balsa de Maspalomas y su entorno más cercano, en Gran Canaria, también podría observarse pues, a pesar de localizarse en un entorno de elevada presión turística, conforma un magnífico ejemplo de interfase entre el medio terrestre y el acuático.

La nómina mediterránea resultaría más completa si se atendiera a humedales como los de la desembocadura del Guadalhorce, en Málaga, notablemente antropizados pero no por ello sin interés; las salinas de San Juan de los Terreros, en Pulpí (Almería), actualmente sin explotación pero con funcionalidad hídrica estacional y comunidades vegetales de carácter halófilo; o las salinas de San Pedro del Pinatar (Murcia), vecinas al sitio Ramsar de Mar Menor, y con interés económico, cultural, paisajístico y ornitológico, por ser hábitat de cría del flamenco (Phoenicopterus roseus). A lo largo de la Costa Blanca se encuentran distintas explotaciones salineras, en ocasiones abandonadas, aunque no por ello sin valor, como las de l'Altet, junto a la ciudad de Alicante; o las de Calpe, al pie del peñón de Ifach y completamente abrazadas por el crecimiento urbano. La alargada llanura litoral valenciana acogía antaño numerosas zonas húmedas, que actualmente se hallan desaparecidas o muy mermadas, como es el caso de los marjales de Xeresa y Xeraco y el de Cullera, que

2 La Ley 4/1989, de Conservación de los espacios naturales y de flora y fauna silvestres preveía, en su artículo 25, la elaboración de un inventario de zonas húmedas: «Por el Ministerio de Agricultura, Pesca y Alimentación con la información suministrada por las Comunidades Autónomas en cuyo territorio se encuentren, se elaborará y se mantendrá permanentemente actualizado un inventario nacional de zonas húmedas, a fin de conocer su evolución y, en su caso, indicar las medias de protección que deben recoger los Planes hidrológicos de cuencas». Sin embargo el primer catálogo exhaustivo (Inventario Nacional de Zonas Húmedas) fue realizado por encargo de la Dirección General de Obras Hidráulicas entre 1989 y 1991, proporcionando datos de unos 1.400 humedales. En 1996 se actualizó dicho inventario (Actualización del Inventario de Zonas Húmedas. Banco de Datos), que elevó en más de un millar el censo de humedales. El RD 435/2004 regulaba el Inventario Español de Zonas Húmedas, mientras que la Ley 42/2007 del Patrimonio Natural y la Biodiversidad, en su artículo 9, recogía de nuevo esta inquietud, estipulando que: «Formará igualmente parte del Inventario Español del Patrimonio Natural y de la Biodiversidad un Inventario Español de Zonas Húmedas, a fin de conocer su evolución y, en su caso, indicar las medidas de protección que deben recoger los Planes Hidrológicos de Demarcación de la ley de aguas». A finales de 2011 las Comunidades autónomas que habían hecho partícipe a la administración central de sus humedales inventariados eran Andalucía, Comunidad de Madrid, Comunidad Valenciana y La Rioja, con un sumatorio total de 237 emplazamientos repartidos en $164493,45 \mathrm{Ha}$. 
preceden por el sur a la Albufera, o los de Almenara y Sagunt, que lo hacen por el norte; o el cauce final del Mijares, hoy más empobrecido que tiempo atrás. La misma mengua y degradación de humedales aparece a lo largo del litoral catalán, donde espacios como las dunas de Torredembarra, que hasta hace unas décadas eran muestra de un tipo de costa habitual, hoy ya no poseen valor por su representatividad, sino por su singularidad en una franja litoral urbanizada sin solución de continuidad. Un caso algo distinto es el de la menorquina albufera des Grau que, encajada en un alargado valle, presenta una morfología más cercana a la de las rías atlánticas que a la de las albuferas de llanura sedimentaria; destaca por sus diferentes profundidades, la importante influencia de aguas dulces, la diversidad de ambientes y también la de organismos, incluidas las aves.

Se extrañan en el listado Ramsar más humedales de alta montaña, como el lago de Sanabria, el mayor de los lagos españoles y el único de cierta entidad formado por la morrena terminal de un extinto glaciar. De la misma manera se echa en falta una representación de las lagunas glaciocársticas de Picos de Europa, que responden a la acción de los hielos cuaternarios sobre un modelado cárstico preexistente, y también una muestra de los sistemas lacustres culminares de Sierra Nevada que, sumados a la Laguna y Turbera de Padul, conforman los relictos glaciares más meridionales de Europa. Otras muestras de interés territorial son la Laguna Negra de Soria o la Laguna Grande de Gredos y su cercana turbera, amén la pléyade de ibones del Pirineo central, de los cuales no se recoge ninguna muestra. Los sistemas cársticos resultarían más completos si contemplaran las torcas conquenses, como el complejo de Cañada del Hoyo, magnífico ejemplo de dolinas de colapso inundadas por el nivel freático, así como otras formaciones de la Ibérica castellana, como la laguna de Taravilla, en Guadalajara. Sin olvidar la incomprensiblemente olvidada Sima de San Pedro, en Oliete (Teruel), de espectacular morfología y gran importancia ornitológica, especialmente para la fauna quiróptera. En cuanto a humedales emplazados en morfologías volcánicas sorprende la falta de representación de las lagunas en cubetas volcánicas del Campo de Calatrava, sin parangón en la Península Ibérica, con un bello ejemplo en la laguna de Fuentillejo, entre media docena más. Éstas solo se pueden comparar en España a las hoy efímeras charcas de las calderas canarias, como la de Bandama, en Gran Canaria, con una fisonomía muy desgastada y antropizada. Caso aparte es la Laguna Verde, o de Los Ciclos, en Lanzarote, cuyo mayor interés reside en la génesis de su formación aunque su atributo más valorado sea el paisajístico.

Las cuencas sedimentarias quedarían oportunamente complementadas si se observaran algunos de los humedales sobre arenas de Tierra de Pinares, entre Valladolid y Segovia, como las lagunas de Cantalejo, que presentan el interés añadido de acoger depósitos de turba. También resultaría valioso aumentar la representación de las tablas, o cauces fluviales de escasa pendiente en los que el río discurre de manera extendida y casi sin mostrar su corriente, como en Villarubia de los Ojos, en Ciudad Real, ahora quizás de menor importancia que antaño. La nómina de humedales salinos podría ampliarse, por ejemplo, considerando las lagunas de Pétrola y Salobralejo (Albacete) y las saladas de Alcañiz y Calanda (Teruel), recordando siempre la lámina de máxima inundación y la orla perimetral de vegetación halófila, en ocasiones muy desarrollada, como sucede en el saladar de Borox (Toledo). De la misma manera debería atenderse a las lagunas ricas en carbonato sódico, llamadas soda lakes en terminología limnológica, tan escasas en Europa y presentes en el sector oriental de la submeseta norte, como en Carpio, Villagonzalo de Coca o Medina del Campo. Contemplar una muestra de las charcas diseminadas por la dehesa, sobre todo por ser éste un hábitat tan singular fuera de la Península Ibérica, pero también por su valor faunístico y paisajístico. Observar, igualmente, algunas de aquellas lagunas desecadas y parcial o totalmente recuperadas, como la de Antela (Ourense), la del Cañizar (Teruel), 
Ivars (Lleida) o la de La Janda (Cádiz), hogaño muy mermada, pero de absoluta importancia para la población europea de ibis eremita (Geronticus eremita). Y recordar, también, espacios con un valor histórico y cultural particularmente significativo, como sucede con los balnearios de las ya citadas lagunas de Pétrola y Medina del Campo, los pequeños humedales asociados al Canal de Castilla o el lago de Carucedo, utilizado en época romana para la explotación aurífera de Las Médulas mediante el procedimiento de ruina montium.

\section{Conclusiones}

Las reflexiones realizadas en torno a los humedales Ramsar españoles facilitan una mejor aproximación a estos espacios naturales protegidos. En un contexto internacional España es uno de los principales países (tercer lugar mundial y segundo europeo) en la aportación de espacios a la Convención, si bien en un contexto interno resulta fácil detectar ciertas irregularidades (la diferencia máxima es de 25 a 1 espacios declarados por Comunidad Autónoma). Territorialmente se observa una evidente polarización hacia el sur ibérico, particularmente en las provincias de Córdoba y Cádiz, que no parece responder a una mayor existencia de zonas húmedas. Tampoco se detectan patrones en la distribución biogeográfica, de hábitats, de importancia paisajística o de dimensión, si bien es cierto que frecuentan los humedales de escasa superficie como parece lógico, por otra parte, en un país de contexto mediterráneo. Por el contrario sí se detecta homogeneidad desde el punto de vista zoogeográfico, cosa coherente con los principios primigenios de la declaración. Así parecen protegidos humedales con valor invernante y con interés migratorio o reproductivo, aunque estas valoraciones nunca pueden realizarse para el conjunto de un humedal sino para un ave en particular, como es el caso de la avutarda (Otis tarda) en Villafáfila, la invernada del ganso común (Anser anser) en Doñana, el paso de la grulla (Grus grus) y la espátula (Platalea leucorodia) por Gallocanta y Santoña, respectivamente, o la reproducción de flamencos (Phoenicopterus roseus) en Fuentedepiedra.

Una caracterización de los humedales Ramsar españoles con perspectiva territorial señala un leve predominio de los humedales interiores ante los costeros, y los mediterráneos respecto los atlánticos, como se colige de la superficie territorial que ocupan. El grado de antropización es elevado, existiendo nueve declaraciones con una influencia humana que, cuanto menos, puede considerarse significativa. En cuanto a morfología resultan abundantes los situados en depresiones endorreicas y en llanos costeros, y escasean los de tipo glacial. El valor ambiental de los espacios declarados es variado, según si se atiende a su papel en cuanto a las aves u otra fauna, la vegetación o los procesos que se desarrollan y las formas que se derivan. En cualquier caso son numerosas las figuras de protección que, aparte de la designación Ramsar, amparan estos lugares.

Los espacios Ramsar se plantearon, en sus inicios, como una selección de aquellos humedales de mayor interés ornitológico. La maduración del Convenio ha permitido acercar esta figura a la protección de zonas húmedas en general, independientemente de su especial valor para las aves. Dicho cambio de planteamiento requiere ajustar criterios en la selección e inclusión de humedales al Convenio, y también en la misma consideración administrativa de estos espacios. En el caso español esta idea topa con distintas dificultades de tipo jurídico y administrativo, hecho que dificulta la creación de un listado consistente y coherente, es decir, una red en sentido estricto, que reúna aquellos humedales de mayor significado en el conjunto estatal. 


\section{Agradecimentos}

Agradezco las interesantes aclaraciones realizadas por un evaluador anónimo sobre el RDL $1 / 2001$.

\section{Referencias bibliográficas}

ALDAYTURRIAGA, I. (1995): La Convención de Ramsar relativa a los humedales de importancia internacional, en LÓPEZ RAMÓN, F. (Dir.) Régimen jurídico de los espacios naturales protegidos. Kronos. Zaragoza, pp. 43-56.

ALFONSO, C. (2002): «Los humedales del mundo a examen», en Ambienta, nº17, pp. 4-11. BÉTHEMONT, J.; HOUSSEL, A. (1992): «Un programme environnemental à l'échelle du bassin Méditerranéen : les zones humides protégées par la Convention de Ramsar» en Mappemonde, 1, pp. 27-29.

BLASCO, D. (2002): «Convenio Ramsar», en Ambienta, nº17, pp. 13-16.

CAMACHO, A. (2008): «La gestión de los humedales en la política de aguas en España» en Panel científico-técnico de seguimiento de la política de aguas. Fundación Nueva Cultura del Agua, 36 p. [Consultable en: < http://www.unizar.es/fnca/varios/panel/14. pdf>. Último acceso: 20 de febrero de 2012].

CASADO, S.; MONTES, C. Guía de los lagos y humedales de España. J.M. Reyero Editor. Madrid, $255 \mathrm{pp}$.

DURÁN VALSERO, J.J.; GARCÍA DOMINGO, A.; ROBLEDO ARDILA, P. (2009): «Propuesta de clasificación genético-geológica de humedales. Aplicación a los humedales españoles incluidos en el Convenio de Ramsar» en Boletín Geológico y Minero, $\mathrm{n}^{\circ} 120,3$, pp. 335-346.

ECOLOGISTAS EN ACCIÓN (2008): Día mundial de los humedales: perdigones de plomo envenenan a 60.000 aves cada año. [Consultable en: < http://www.ecologistasenaccion. org/spip.php?article10366>. Último acceso: 20 de febrero de 2012].

EUROPARC (2010): Anuario Europarc-España del estado de los espacios naturales protegidos 2009. FUNGOBE. Madrid, 100 pp.

JUNTA DE ANDALUCÍA (2004): Plan andaluz de humedales. Consejería de Medio Ambiente, 263 pp.

KEDDY, P. (2002): Wetland Ecology. Cambridge University Press. Cambridge, 614 pp.

MACKAY, H.; FINLAYSON, C.M.; FERNÁNDEZ-PRIETO, D.; DAVIDSON, N.; PRITCHARD, D.; REBELO, L-M. (2009): «The role of Earth Observation (EO) Technologies in supporting implementation of the Ramsar Convention on Wetlands» en Journal of Environmental Management, ${ }^{\circ} 90$, pp. 2234-2242.

MALLARACH, J.M. (1999): Criteris i mètodes d'avaluació del patrimoni natural. Barcelona. Departament de Medi Ambient, 106 pp.

MANZANO, M.; BORJA, F.; MONTES, C. (2002): «Metodología de tipificación hidrológica de los humedales con vistas a su valoración funcional y a su gestión. Aplicación a los humedales de Doñana» en Boletín Geológico y Minero, n¹13, 3, pp. 313-330.

MARTÍN MATEO, R.(1981): «La protección de las zonas húmedas en el ordenamiento español» en Revista de la Administración Pública, nº96, pp. 7-31.

MITSCH, W.; GOSSELINK, J. Wetlands. John Wiley \& Sons. New York, 920 pp.

MULERO, A. (2002): La protección de los espacios naturales en España. MundiPrensa. Madrid, $309 \mathrm{pp}$.

MULERO, A. (2004): «Iniciativas internacionales para la protección de espacios naturales. Un análisis crítico de su aplicación en España», en Documents d'Anàlisi Geogràfica, nº44, pp. 167-187. 
MUÑOZ, V.; NEGRO J.J.; GREEN, A. (2008): «Malvasía canela, un invasor al que temer y contener» en Quercus, 269, pp. 14-20.

OAPN (1999): Plan estratégico español para la conservación y el uso racional de los humedales. Ministerio de Medio Ambiente. Madrid, 88pp.

PARACUELLOS, M. (2007): «Islas de agua en un mar de tierra» en Quercus, 260, pp. 20-24.

PEARCE, F.; CRIVELLI, A.J. (1994): Characteristics of Mediterranean Wetlands. Tour du Valat. Arles, $89 \mathrm{pp}$.

POLO, M. (2010): «Las aves reflejan la pérdida de habitats en Corrubedo» en Quercus, 297, pp. 26-30.

RAMSAR BUREAU (1971): Copia certificada de la Convención relativa a los humedales de importancia internacional especialmente como hábitat de aves acuáticas. Ramsar, Irán, 2 de febrero de 1971. Modificada según el Protocolo de París, de 3 de diciembre de 1982 y las Enmiendas de Regina, de 28 de mayo de 1987. [Consultable en: <http:// www.ramsar.org/cda/es/ramsar-documents-texts-convention-on/main/ramsar/1-3138\%5E20671_4000_2_>. Último acceso: 20 de febrero de 2012].

RAMSAR BUREAU (2005): An Integrated framework for wetland inventory, assessment and monitoring (IF-WIAM). [Consultable en: < http://www.ramsar.org/pdf/key_guide_framework_inventory_e.pdf $>$. Último acceso: 20 de febrero de 2012].

RAMSAR BUREAU (2009): Stratergic framework for the List. [Consultable en: < http:// www.ramsar.org/pdf/key_guide_list2009_e.pdf>. Último acceso: 20 de febrero de 2012].

RAMSAR BUREAU (2011): The Ramsar list of wetlands of international importance. [Consultable en: <http://www.ramsar.org/cda/en/ramsar-documents-list/main/ramsar/1-31-218_4000_0_> Último acceso: 20 de febrero de 2012].

REY BENAYAS, J.M.; PÉREZ PÉREZ, C.; GONZÁLEZ BERNÁLDEZ, F.; ZABALETA FRANCO, M. (1990): «Tipología y cartografía por fotointerpretación de los humedales de las cuencas del Duero y del Tajo», en Mediterránea serie Biológica, n¹2, pp. 5-26.

RODRÍGUEZ GARCÍA, J.; PÉREZ-GONZÁLEZ, A. (1999): «Clasificación geomorfológica de los humedales y fondos endorreicos de La Mancha centro-occidental» en Geogaceta, n²6, pp. 83-86.

SANZ DONAIRE, J.J. (2000): «Descriptive and functional wetland typology and classification» en: Observatorio Medioambiental, n³, pp. 311-339.

SCHNACK, J. (2006): «Why wetlands?», en Oecologia Brasiliensis, vol. 10, n 2, pp. 127-134.

SGHN (2012): Comunicado de prensa da SGHN sobre a situación na Lagoa da Frouxeira. [Consultable en: <http://www.sghn.org/>. Último acceso: 20 de febrero de 2012].

SORIA, J.M.; MIRACLE, M.R.; VICENTE, E. (1987): Aporte de nutrientes y eutrofización de la Albufera de Valencia, en Limnetica, n³ (2), pp. 227-242.

SUÁREZ, C.; URÍOS, V. (1999): «La contaminación por saturnismo en las aves acuáticas del parque natural de El Hondo y su relación con los hábitats alimenticios» en: Humedales Mediterráneos, 1, pp. 83-90.

TROITIÑO, M.A.; de MARCOS, F.J.; GARCÍA, M.; del RÍO, M.I.; CARPIO, J.; de la CALLE, M.; ABAD, L. (2005): «Los espacios protegidos en España: significación e incidencia socioterritorial» en Boletín de la AGE, 39, pp. 227-265.

U.S. FISH AND WILDLIFE SERVICE (2010): Wetlands Mapper. Documentation and Instructions Manual. National Wetlands Inventory. Division of Habitat and Resource Conservation. Madison, 18 p. [Consultable en: < http://www.fws.gov/wetlands/Data/ Mapper.html>. Último acceso: 20 de febrero de 2012].

VIÑALS, M.J. (1999): «La variabilidad de las cubetas de los humedales mediterráneos: formas y procesos geomórficos» en Humedales Mediterráneos, 1, 91-98. 